Universidad de Lima

Escuela de Posgrado

Maestría en Dirección de Operaciones y Proyectos

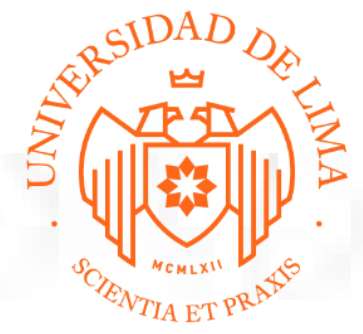

\title{
PROPUESTA DE MEJORA DEL SERVICIO LOGÍSTICO DE UNA EMPRESA 3PL, IMPLEMENTANDO LA METODOLOGÍA \\ LEAN SIX SIGMA
}

Trabajo de Investigación para optar el Grado Académico de Maestro en Dirección de Operaciones y Proyectos

Max Raúl Vargas Sánchez

19882655

Carlos Alberto Zegarra Chang 20172980

Asesor: Raúl Saco Vértiz Guerrero

Lima - Perú

Agosto, 2019 